\title{
A Personalized Update on IgA Nephropathy: A New Vision and New Future Challenges
}

\author{
Eduardo Gutiérrez ${ }^{\mathrm{a}, \mathrm{b}}$ Fernando Carvaca-Fontán ${ }^{\mathrm{a}, \mathrm{c}}$ Leonella Luzardo ${ }^{\mathrm{d}}$ \\ Enrique Morales ${ }^{\mathrm{a}, \mathrm{c}}$ Marina Alonso ${ }^{\mathrm{a}, \mathrm{e}}$ Manuel Praga ${ }^{\mathrm{a}, \mathrm{c}}$
}

anstituto de Investigación Hospital 12 de Octubre (i+12), Madrid, Spain; 'bepartment of Nephrology, Hospital Universitario 12 de Octubre, Madrid, Spain; ' Department of Medicine, Universidad Complutense de Madrid, Madrid, Spain; d Department of Nephrology and Pathophysiology, School of Medicine, Universidad de la

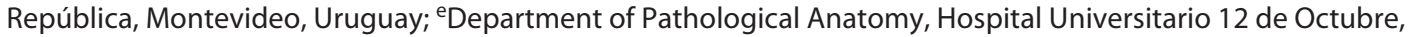
Madrid, Spain

\section{Keywords}

$\lg$ A nephropathy $\cdot$ Proteinuria and hematuria $\cdot$ Oxford Classification $\cdot$ Complement pathways $\cdot$ Corticosteroids

\begin{abstract}
$\lg$ A nephropathy (IgAN) is the most common primary glomerulonephritis in the world among patients undergoing renal biopsy. Approximately $30 \%$ of patients with IgAN develop end-stage kidney disease 20 years after renal biopsy. It is a glomerulopathy with a very broad clinical presentation, making it difficult to stratify and treat. IgAN is characterized by dysregulation of the immune system, which causes an abnormal synthesis of IgA 1 that is deglycosylated causing its mesangial deposition. IgAN pathogenesis is incompletely understood; the current multi-hit hypothesis of IgAN pathogenesis does not explain the range of glomerular inflammation and renal injury associated with mesangial IgA deposition. Although associations between IgAN and glomerular and circulating markers of complement activation are estab-
\end{abstract}

lished, the mechanism of complement activation and contribution to glomerular inflammation and injury are not defined. On the other hand, the renal-gut connection can also play an important role in the pathogenesis of IgAN with possible therapeutic implications. In order to standardize the histological findings, the Oxford Classification has allowed clarifying renal lesions that confer potential risk of progression. Currently, except for the blockade of the renin-angiotensin-aldosterone system, no other therapies are available in clinical setting for the treatment of $\lg \mathrm{AN}$, although the range of new drugs under investigation is extensive. The incorporation in the next trials of clinical parameters such as the amount of hematuria and histological lesions may allow more personalized therapeutic approaches. To summarize, in recent years, several important efforts have taken place in the understanding of IgAN, but still, further studies are warranted to elucidate the best therapeutic strategies according to the risk to improve the prognosis of this entity.

(c) 2020 S. Karger AG, Basel

$\begin{aligned} & \text { karger@karger.com } \\ & \text { www.karger.com/nef }\end{aligned}$
Karger ${ }^{\prime /}$




\section{Introduction, IgA Nephropathy Overview}

"Who knows the question, knows the half" Herb Boyer

IgA nephropathy (IgAN), Berger's disease (described in 1968) [1], is the most common primary glomerulonephritis in the world among patients undergoing renal biopsy [2]. It is a very common form of primary glomerulonephritis that affects about 200,000-350,000 people per year globally [3]. Its diagnosis is associated with a reduction in life expectancy between 6 and 10 years [4]. Its incidence has also been associated with poor socioeconomic situations [5]. The geographical distribution of the IgAN is very diverse. IgAN is more frequent in Asian populations, especially in Southeast Asia, and much less frequent in the African population. The distribution in Europe is also heterogeneous with predominance in the north and east of the continent. Although referral policies to the nephrologist as well as school screenings influence these data, there must be ethnic and genetic components that can partly explain these differences. An updated vision of the IgAN points to the need to consider this pathology as an entity closely linked to environmental factors, lifestyle, and diet. In addition to the strong association established with genetic factors, there are data on the possible influence of local pathogens with the development of this glomerulonephritis, especially with parasitic helminth infections $[6,7]$. The discovery of new pathogenic mechanisms, especially the role of complement, forces us to change the vision of this entity with the need for an individualized approach with personalized therapy.

Classically, it has been affirmed that $30 \%$ of patients with IgAN, older than 30 years, develop terminal chronic renal failure at 20 years of age after performing the renal

Fig. 1. Pathogenesis of IgAN. Graphical illustration of the multihit hypothesis for the pathogenesis of the disease. a The production of mucosal IgA may be induced by T-cell-dependent or T-cellindependent mechanisms. The secretion of several cytokines such as interleukin-6, interleukin-10, BAFF, and APRIL by dendritic cells induce B-cells to undergo class switching recombination from IgM to IgA1. IgA-secreting plasma cells migrate to the mucosal lamina propria and release dimeric IgA1 into the lumen. Some misdirected IgA-secreting cells are released to the systemic compartment where they take up residence in systemic sites and secrete poorly $\mathrm{O}$-galactosylated IgA1 to systemic circulation. b Several genetic and environmental factors may predispose IgA patients to mount abnormal immune responses to certain common pathogens. This genetic background can also modulate the IgAN phe- biopsy [8]. However, this premise must be qualified after the important contributions of the Canadian Registry with 542 patients with biopsy-proven IgAN. In this study, Reich et al. [9] demonstrated, for the first time, how the amount of mean proteinuria during follow-up is significantly associated with the development of end-stage kidney disease (ESKD). This study revealed that proteinuria during follow-up was the most important predictor of loss of kidney function. The rate of decline of estimated glomerular filtration rate (eGFR) increased with the amount of proteinuria establishing a close relationship between proteinuria and progression. However, IgAN is characterized by a broad range of clinical presentations and courses. This translates into different presentations in children and adults. Furthermore, clinical severity differs markedly with gender, ethnicity, and race. It is estimated that in $5.8 \%$ of cases, there may be a family history or genetic predisposition for the disease [10]. Hence, it is thought that IgAN can encompass different biological processes, which presents the question of whether IgAN is a single pathogenic entity. Stratification of patients on clinical and histology features is currently difficult, which greatly complicates the therapeutic approach. Often, the clinical presentation (especially for asymptomatic proteinuria and hematuria) occurs years before renal biopsy.

IgAN is an autoimmune disease characterized by abnormal of IgA1 synthesis and glycosylation, resulting in imbalanced increase of circulating galactose-deficient IgA1 (gd-IgA1). This anomalous IgA1 can form complexes with specific autoantibodies, forming gd-IgA1 immune complexes (gd-IgA1-IC). The gd-IgA1-IC deposit in glomeruli and induce the development of mesangial proliferation and matrix expansion by complex mechanisms not fully elucidated [11].

The most consistent clinical finding in IgAN is the presence of hematuria; however, proteinuria, the pres-

notype. c TLR ligation from mucosal-derived pathogen-associated molecular patterns cause polyclonal lymphocyte proliferation. Specific reactive $\operatorname{IgG}$ and $\operatorname{IgA}$ antibodies against gd-IgA1 are formed and ultimately result in immune complex formation. d Immune complexes get trapped in the mesangium through an increased affinity of gd-IgA1 for extracellular matrix components and trigger inflammatory pathways, which result in glomerular injury and tubulointerstitial scarring. e A growing body of evidence have implicated complement activation (particularly the alternative, lectin, and terminal pathway) in the pathogenesis of IgAN, both amplifying and perpetuating inflammation and renal injury. IgAN, IgA nephropathy; BAFF, B-cell activating factor; APRIL, a proliferation inducing ligand; gd-IgA1, galactose-deficient IgA1.
(For figure see next page.) 

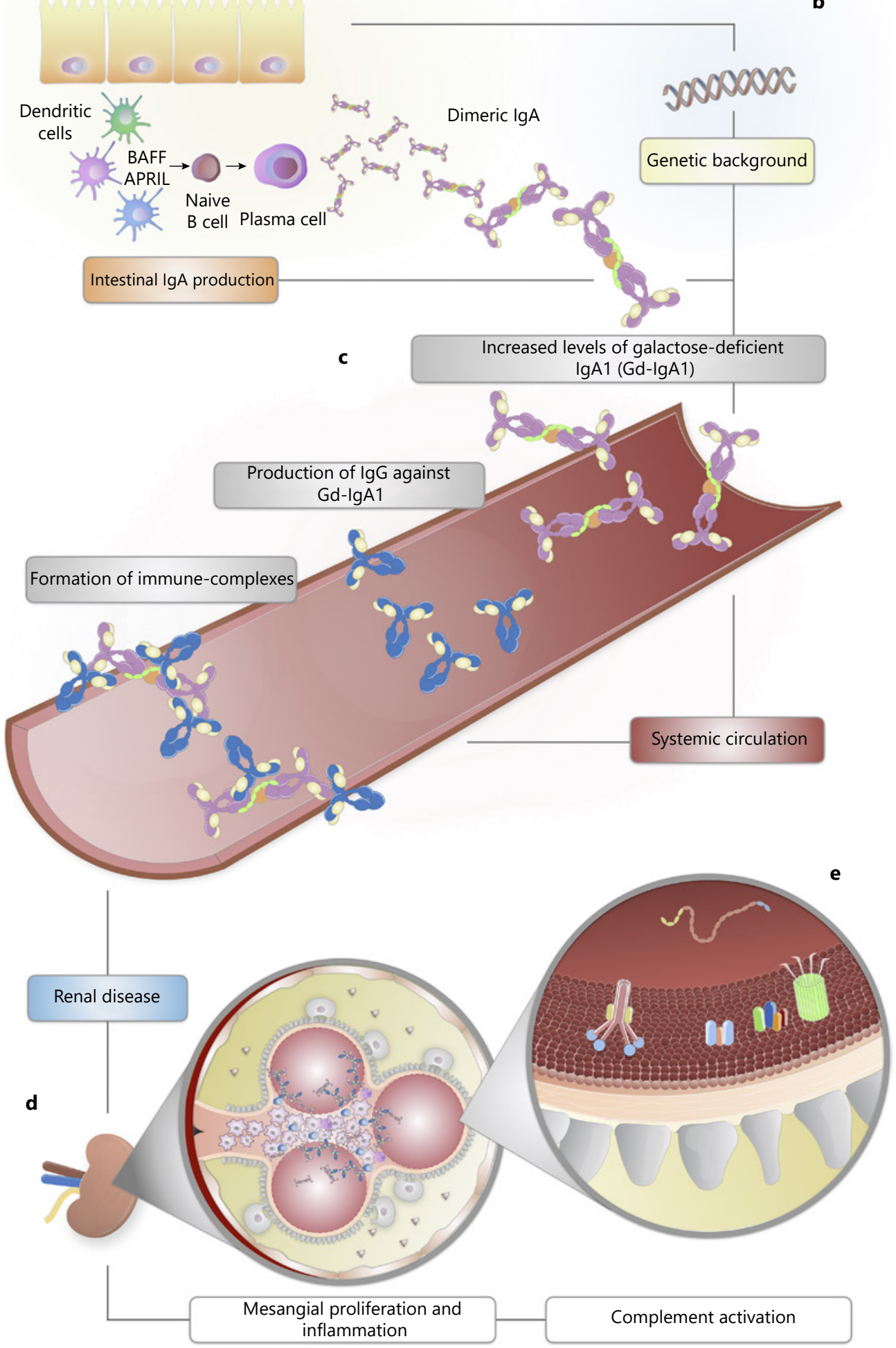
ence or development of arterial hypertension, and reduced eGFR at diagnosis are the clinical factors that influence the development of CKD. The amount of proteinuria has been significantly related with worse renal outcomes [9]. Consequently, all therapeutic measures have been directed to the reduction of proteinuria. Despite this, in recent years, and following the implication of new pathogenic pathways, numerous randomized clinical trials (RCTs) are being designed directly aimed at their pathogenesis. It is well known that its clinical variability and its long evolution time make it difficult to have a homogeneous treatment. Recent advances in pathogenesis, the relentless search for valid biomarkers, and the incorporation of new variables (hematuria, histology, complement activity, etc.) can lead to a radical change in the therapeutic approach to this complex pathology.

\section{Pathogenesis}

IgAN is an autoimmune disease influenced by multiple genetic, ethnic, and environmental factors. Although the protagonist seems to be gd-IgA1, multiple events contribute to IgAN and renal damage. The currently accepted model of pathogenicity in IgAN is the "four-hit" model [12] (see Fig. 1).

\section{First Hit: Elevated Serum Gd-IgA1 Levels}

IgA is the most synthesized antibody in humans, abundant on mucosal surfaces, and fundamental to mucosal antigen responses and host-commensal homeostasis. There are 2 IgA subclasses, IgA1 and IgA2. About $80 \%$ of serum $\operatorname{IgA}$ is $\operatorname{IgA1}$, and this is the main in $\operatorname{IgAN}[13]$. IgAN patients show greater proportions of poorly $\mathrm{O}$-galactosylated IgA1 in circulation compared to healthy individuals $[14,15]$. The gd-IgA1 glycoforms are polymeric and normally produced at mucosal surfaces as part of innate immune responses [16]. Therefore, abnormal innate immunity responses to mucosal infections or antigens may be involved in the gd-IgA1 production in IgAN. Supportive of this, a role for TLR, which cause polyclonal lymphocyte proliferation and formation of circulating immune complexes $[17,18]$, may be involved in IgAN pathogenesis. Mucosal TLR-9 activation induces B-cell activating factor (BAFF) overexpression in dendritic cells, B-cell expansion, and increased IgA synthesis. By other hand, the same TLR-9 activation induced the production of proliferation-inducing ligand (APRIL) and IL6 , and APRIL and IL-6 act together to promote the generation of gd-IgA1 [19, 20]. Therefore, mucosal-associat- ed lymphoid tissue might be a potential therapeutic target in IgAN. In this way, therapeutic interventions with hydroxychloroquine (HCQ) or BAFF and APRIL inhibitors can have a beneficial effect on patients with IgAN (see Treatment section).

\section{Second Hit: Anti-gd-IgA1 Antibodies}

Gd-IgA1 is the target for antiglycan autoantibodies. Anti-gd-IgA1 IgG levels correlate with disease severity, specifically with the amount of proteinuria. Also, their presence in renal biopsies correlates with mesangial and endocapillary proliferation [21].

\section{Third Hit: Increased Circulating Gd-IgA1 Immune}

\section{Complexes (IC)}

IgAN is characterized by mesangial deposition of IgA1 and complement proteins, especially C3 (80-90\%). The IgA1 deposits derive from pathogenic circulating IC and contain aberrantly glycosylated polymeric IgA1. The mesangial cells represent the primary target of these pathogenic immune deposits, and the unique anatomy of the mesangium, located between the fenestrated endothelium and the glomerular basement membrane, makes it a deposit focus. Gd-IgA1-IC deposition can be increased during episodes of macroscopic hematuria, perhaps after binding receptors that recognize the pathogenic IC [22].

\section{Fourth Hit: Mesangial Cell Proliferation, Glomerular Inflammation, and Renal Injury}

This is characterized by extracellular matrix expansion, complement activation, and cytokine release. Some cytokines can injure podocytes, alter podocyte gene expression and glomerular filtration and induce proteinuria [23]. Mesangial cells have IgA receptors and are candidates for IC clearance, initiation of injurious mechanisms, and localizing complement activation. The tissue deposition of IgA1-IC can trigger local complement activation, but it is not well known how it occurs. Mesangial cells are fundamental to maintain glomerular stability, and mesangial cell stress can influence podocyte behavior and explain the podocytopathy of IgAN. The mesangium-podocyte cross talk can justify the appearance of proteinuria and tubulointerstitial damage, and the release of cytokines as a tumor necrosis factor, IL-6, and angiotensin II could induce inflammation and subsequent glomerulosclerosis. Thereby, hematuria could be involved in mesangial expansion and podocyte damage through mechanisms including mesangial architecture modification.

Many components of IgAN pathogenesis are known. However, we do not understand the spectrum of glomer- 
Fig. 2. Evidence of complement activity in IgAN and its potential prognostic role (adapted from Tortajada et al. [24]). IgAN, IgA nephropathy.

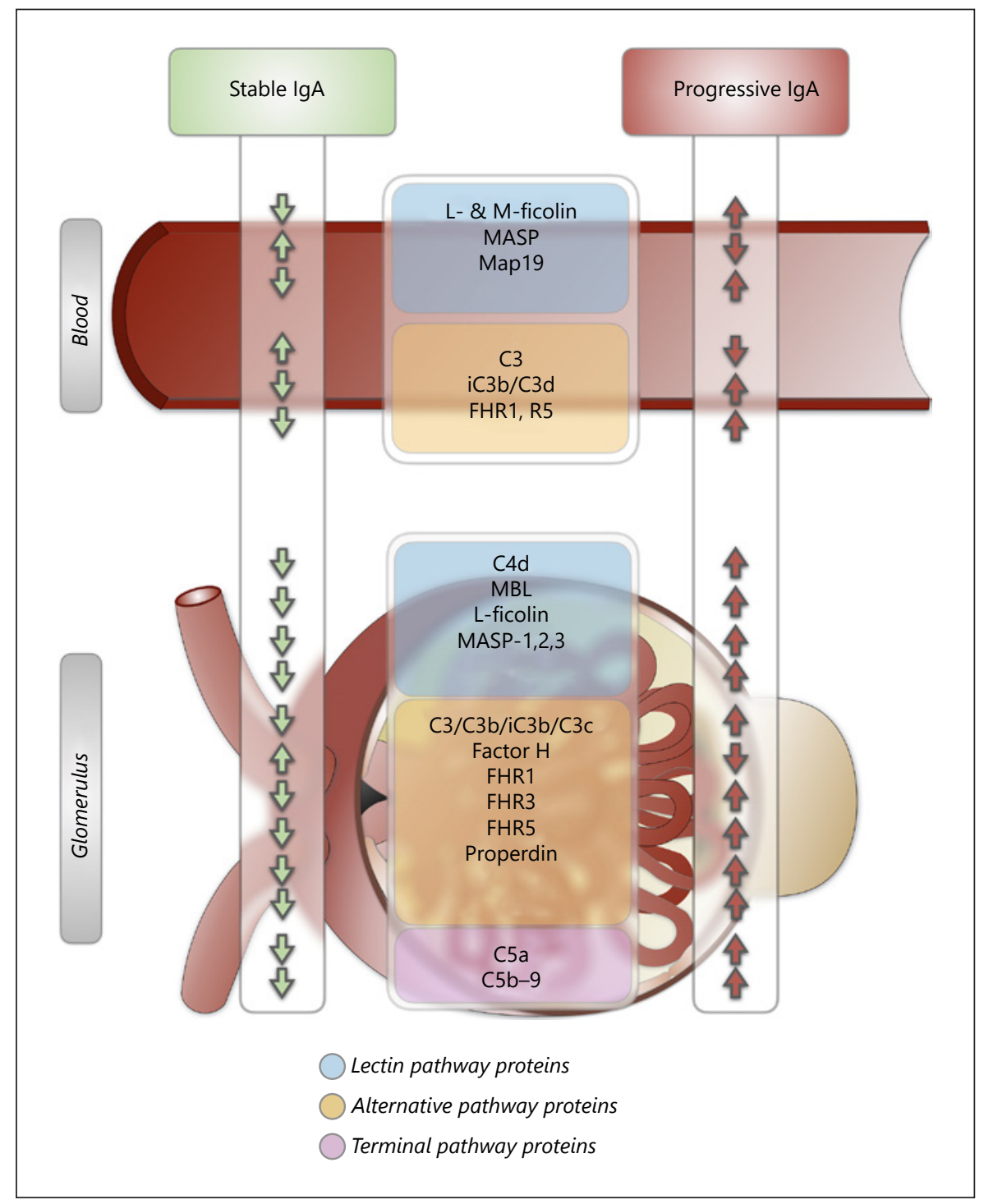

ular responses to deposited gd-IgA1 seen in IgAN. A growing body of evidence suggests the alternative: lectin and terminal complement pathways influence glomerular inflammatory and injurious responses to deposited IgA1 and contribute to IgAN disease severity [24].

\section{The Important Role of Complement in IgAN}

The alternative pathway (AP) is the main complement cascade activator in IgAN and is principally responsible for C3 deposition. Glomerular C3 deposits may help differentiate IgAN from isolated lanthanic IgA deposits found in up to $4-16 \%$ of the population $[25,26]$. Recent evidence of factor H-related protein (FHR) 1 and FHR5 involvement indicates a role for the AP in IgAN patho- genesis. FHR proteins modulate FH function by competition with ligands and deregulate complement activation on cell surfaces. Genome wide association studies have identified protective associations for IgAN within the $\mathrm{CFH}$ locus on chromosome 1q32. The deletion of the FHR1 and FHR3 genes (delFHR3-R1) associates with protection from IgAN [27]. Interestingly, allele frequencies correlate with IgAN epidemiology and may partly explain the geographical distribution of this pathology. The protective delFHR3-R1 allele is more prevalent in African populations (up to 50\%) where there is lower disease prevalence, while in East Asia, with a high prevalence, deletion is only evident in $0-5 \%$ of the population $[28,29]$. Two independent studies showed FHR1 plasma 
levels were significantly higher in IgAN patients than controls and the authors also observed a negative correlation between FHR1 levels and eGFR [30, 31]. FHR1/FH ratio also associated with disease progression to ESKD [32]. In turn, FHR5 protein plasma levels were higher in IgAN patients than control in 2 large cohorts (Europe and Asia). In addition, serum FHR5 levels correlated with histologic markers of renal injury in both cohorts [30, 33]. Remarkably, FHR1 and FHR5 have been observed in renal biopsies of IgAN with complement-activating products, reflection that they are important and independent players in AP dysregulation.

The lectin pathway (LP) is a plausible link between gdIgA1 deposition and glomerular inflammation in IgAN pathogenesis. IgA an LP are important mediators of innate immunity in respiratory and gastrointestinal tract. Glomerular LP deposition associates with IgAN severity. Mesangial C4, and particularly the activation fragment $\mathrm{C} 4 \mathrm{~d}$, has been identified in renal biopsies of patients with progressive IgAN and reflects the activation of LP. Two different well-characterized Spanish studies have shown that the glomerular positive C4d staining was a significant predictor of ESKD [34, 35].

Finally, terminal complement pathway activity may also be important to IgAN pathogenesis. C5b-9 deposition is associated with renal inflammation and progression of glomerulosclerosis in IgAN [36]. In short, the complement and its different components seem to exert a fundamental prognostic influence in patients with IgAN (see Fig. 2).

\section{Clinical Presentation}

The spectrum of clinical manifestations in IgAN is wide, from incidental asymptomatic microscopic hematuria, to a rapidly progressive forms leading to kidney failure. However, the most common presentation in clinical settings is microhematuria and moderate proteinuria with relatively preserved kidney function. The clinical manifestations of the disease may be preceded by an infection with intrainfective macrohematuria in some cases.

IgAN may have different clinical courses ranging from spontaneous remissions in a low number of individuals ( $<5 \%$, poorly studied) [37] to rapid deterioration of renal function also in a few cases (5-10\% of patients) to the slowly progressive deterioration of renal function over prolonged follow-up, probably the most frequent form of clinical presentation. Nonetheless, it is also important to note that many patients do not progress at all.
Macroscopic hematuria and proteinuria following an upper respiratory tract infection may be one of the typical forms of presentation, especially in children and early stages of the disease in adults. Registration studies have shown different clinical presentation patterns according to age range [38]. Furthermore, clinical severity differs markedly with gender, ethnicity, and race.

Hematuria is the most consistent clinical finding and approximately half of patients present with outbreaks of macroscopic gross hematuria. Macroscopic gross hematuria can cause acute kidney injury (AKI), and 25\% of patients over 50 years, with outbreaks beyond 10 days and baseline renal failure, do not return to their previous renal function [39]. Nevertheless, in patients who do not develop AKI, it has traditionally been considered as a favorable marker for good outcome. Tubular damage caused by the hemoglobin released by the RBCs in the tubular lumen is one of the main mechanisms responsible for AKI [40]. Elderly patients with CKD are more susceptible to the deleterious effect of these outbreaks. Recently, a retrospective multicenter study with 151 patients $\geq 65$ years of age has been published that shows that AKI is a very common form of presentation (40\%) [41]. In $86 \%$ of cases, AKI was related to macroscopic hematuria (tubular necrosis associated with erythrocyte casts). Among hematuria-related AKI, $34 \%$ of patients were receiving oral anticoagulants. This could be one of the possible theories that explain the increase in this clinical presentation among elderly patients. Brodsky et al. [42] published for the first time data suggesting that warfarin therapy can induce AKI by glomerular hemorrhage and renal tubular obstruction by RBC casts. Of the 9 initial cases described, 33\% had a renal biopsy of IgAN and renal tubules with diffuse accumulation of dysmorphic erythrocytes (characteristic picture). Six of the 9 patients were over 60 years old. A possible association between warfarin therapy and AKI in patients with IgAN should be evaluated.

However, AKI may also be due, in a small percentage of patients $(\sim 5 \%)$, to rapidly progressive forms of glomerulonephritis (crescents $>50 \%$ ). Several studies have reported that the renal survival of patients with rapidly progressive forms of glomerulonephritis-IgAN is much poorer than in the rest of IgAN clinical presentations. Different series have shown that renal survival in cases of crescentic IgAN is only $50 \%$ at 1 year, and $20 \%$ at 5 years [43]. In rapidly progressive forms (crescents $>50 \%$ ), there are no consistent controlled studies, but small studies have shown the benefit of using combined treatment with steroids and cyclophosphamide [44]. 
IgAN usually associates arterial hypertension and in a small percentage of patients (7-15\%), malignant arterial hypertension is uncommon as a form of clinical presentation. The presence of hypertension is always a negative prognostic factor. Hypertension at presentation has a robust association with an increased risk of eGFR loss. This observation is consistent in all cohorts from different countries and ethnic groups. The risk of developing ESKD over time is much higher in the group of patients with hypertension. However, arterial hypertension is a modifiable factor, and its correct control during follow-up (blood pressure $[\mathrm{BP}]$ averaged) is a better prognostic predictor than its presentation values [45]. On the other hand, malignant hypertension has a remarkably worse renal outcome and only few patients presented features of thrombotic microangiopathy [46].

\section{Proteinuria}

Sustained proteinuria, typically $>1 \mathrm{~g} /$ day, is the strongest prognostic factor in IgAN. The development of proteinuria is essential for increasing the risk of progression in all populations with IgAN. Although there is no prospective evidence, the influence of proteinuria on the rate of progression has been carried out in retrospective studies with an important number of patients and with a prolonged follow-up [9, 47]. In them, it was observed that an average proteinuria $>0.5-1 \mathrm{~g} /$ day was associated with a poor renal prognosis.

The amount of proteinuria continues to be the main inclusion criteria of patients in RCTs. The analysis of its variations, together with the progression toward renal failure, also continues to be the main outcomes of RCTs. However, it is very important to highlight that proteinuria in IgAN can be the result not only of active histological lesions but of glomerular sclerotic lesions with hyperfiltration and tubular damage.

Thompson et al. [48], in a very relevant study, analyzed 13 controlled trials (doubling serum Cr, ESKD, or death). Following this analysis, the sustained reduction in proteinuria $<0.5 \mathrm{~g} /$ day emerges as the most related factor with the best kidney outcome. Even so, and despite the almost normalization of proteinuria, the minimal magnitude and duration of proteinuria reduction that confers a protective effect is still unknown and should be studied in depth in future studies.

Nephrotic syndrome (NS) is uncommon ( 5\%) in IgAN, and when present, it is usually associated with severe histologic features and kidney failure. It is unusual for patients with IgAN and NS to present with only mild mesangial lesions [49]. The few published studies reinforce the idea that these cases may represent dual glomerulopathy. In these patients, the ultrastructural study typically reveals diffuse foot process effacement without peripheral capillary wall immune disease, reminiscent of minimal change disease. In our opinion, we believe that these cases represent mild IgAN with superimposed primary podocytopathy (especially minimal change disease). In this group of patients, NS is usually correlated with the degree of effacement, a finding consistent with the hypothesis of dual glomerulpathy. Usual initial treatment consisted of corticosteroids, although many patients required additional agents to maintain remission status [50].

\section{Hematuria, Is Your Time Now?}

In 1926, Thomas Addis stated that: "The examination of the urine is the most essential part of the physical examination of any patient" [51]. Despite this old and correct statement, hematuria continues to play a residual role in the analysis of a patient with IgAN. However, we must not forget that hematuria is a cardinal element of this pathology and is in its own definition. The behavior of microhematuria is diverse, while in some patients, it may disappear spontaneously or decrease during follow-up and in other cases, it remains stable for long periods of time in general in close correlation with the presence of proteinuria. Nor should we forget that in order to use the term of complete remission, we must confirm the disappearance of microhematuria. Several works have demonstrated their prognostic value not only in $\operatorname{IgAN}[52,53]$.

However, taking as a reference the recommendations of the Kidney Disease Improving Global Outcomes (KDIGO) guidelines, the risk of progression toward ESKD of a patient with IgAN is determined by the mean proteinuria during follow-up, glomerular filtration rate, and $\mathrm{BP}$ [54]. A possible explanation for the lack of interest in hematuria is that study techniques may be inaccurate and require more advanced methods for analysis.

Sevillano et al. [55] have recently published an exhaustive analysis on the prognostic role of average hematuria in 112 patients with biopsy-proven IgAN after a mean follow-up of 14 years. The multivariable analysis showed that time-average (TA) hematuria and time-average proteinuria, as well as baseline renal function and the presence of tubulointerstitial fibrosis in the biopsy, were independent predictors of ESKD. Patients with persistent microhematuria (mean $24 \mathrm{RBCs} /$ per high field [phf]) and proteinuria $>0.75 \mathrm{~g} /$ day were those with the worst renal prognosis. The most important teaching of this study is to answer the following question: What happens when microhematuria disappears? 

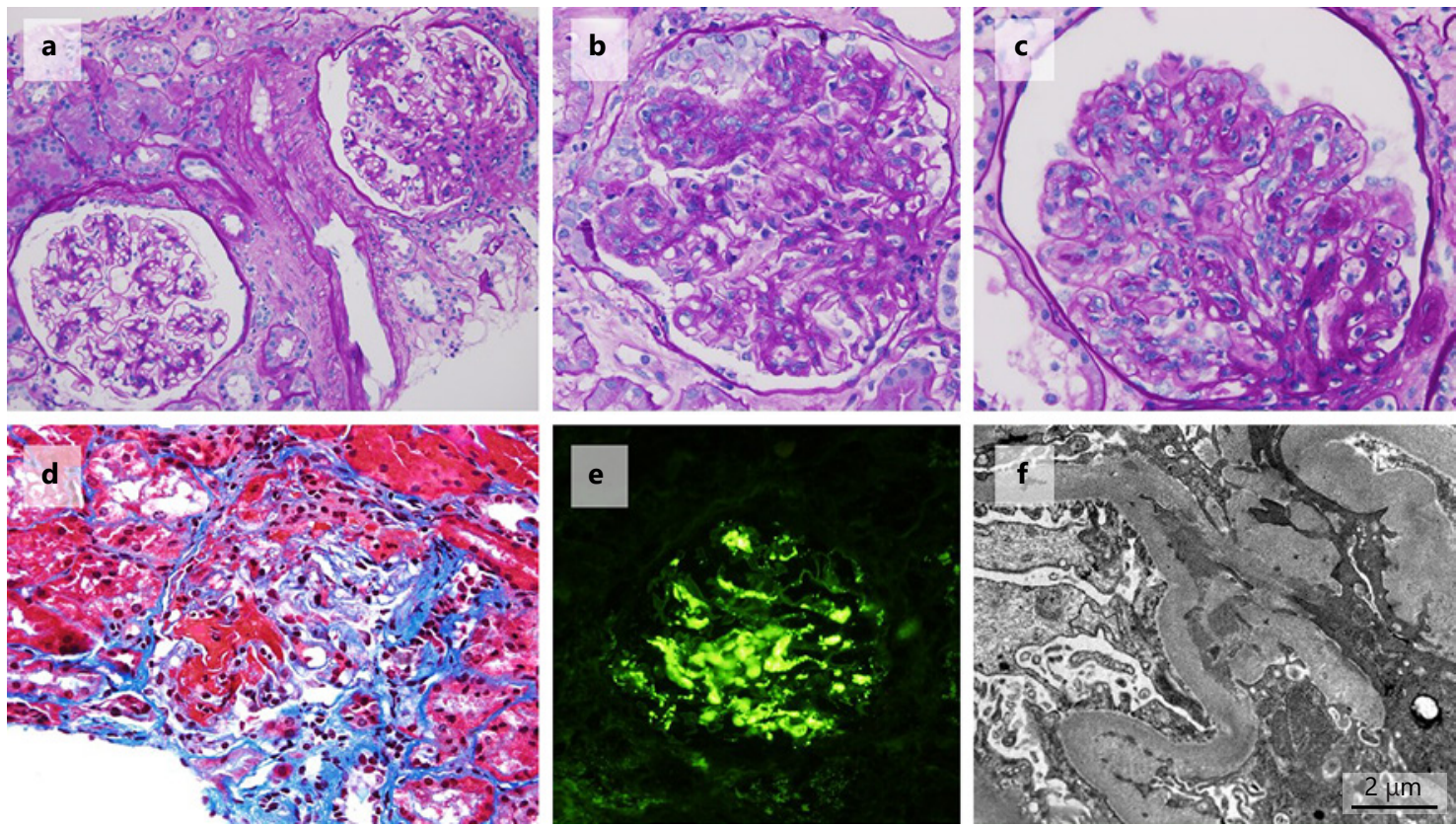

Fig. 3. Different histological lesions in IgAN. IgAN may exhibit variable lesions. In this case (a, PAS stain, $\times 20)$, there is one unremarkable glomerulus (left), while the other one shows mesangial proliferation (right) (Oxford Classification M1, E0, S0, T0, and C0). PAS stain, $\times 40$, shows one glomerulus with mesangial and extracapillary proliferation (Oxford Classification M1, E0 S0 T0 C1) (b) In PAS stain, $\times 40$, there is prominent endocapillary proliferation (Oxford classification M1 E1 S0 T0 C0) (c). Although more common in IgA vasculitis, IgAN may also show necrotizing segmental lesions (d, Masson trichrome stain, $\times 40$, Oxford Score M1, E0, S1, T0, and C1). All these patterns share common features on IF: bright mesangial deposition of IgA (e). Last, electronic microscope studies show mesangial electron-dense deposits (f). IgAN, IgA nephropathy.

In $46 \%$ of this cohort, there was a disappearance of microhematuria that was accompanied by a very significant decrease in the loss of eGFR: from $-6.45 \mathrm{~mL} / \mathrm{min} / 1.73 \mathrm{~m}^{2}$ to $-0.18 \mathrm{~mL} / \mathrm{min} / 1.73 \mathrm{~m}^{2}$ after the disappearance of hematuria. The main value of this study is that it evaluates the association between hematuria and its evolution over time.

Nevertheless, the recent KDIGO Controversies Conference [56] still does not recognize the prognostic value of hematuria due to the absence of more robust data on its independent association with histology (MEST-C score) or other recognized clinical parameters. In order to modify these criteria, a recent publication establishes an association between the amount of hematuria and histology (M1, E1, and C $\geq 1$ ) and confirms that the amount of hematuria is an independent predictor of the loss of eGFR after adjustment by clinical and histological parameters [57]. Severe microhematuria, defined as $>21$ RBCs/ hpf was associated with the greatest loss of eGFR.

If we take these studies as a cornerstone, we can affirm that the current question is how to consider a change in hematuria to surrogates marker of therapeutic efficacy in RCTs examining novel regimens for IgAN. However, Kincaid-Smith et al. [58] already describes the course of 3 young men with aggressive IgAN demonstrating the association between hematuria and proliferative lesions (crescents) as the following sentence reads: "...persistently high microhematuria indicates a continuing activity in the form of focal and segmental crescents" [59].

These studies have shown that an IgAN patient with proteinuria and sustained microhematuria does not have the same clinical behavior as patients with proteinuria without hematuria in which the prognosis is more benevolent. In summary, if we want to select the patients with the highest risk of progression (and future RCTs), we must take into account the combination of high-risk features: sustained proteinuria $>1 \mathrm{~g} /$ day, severe hematuria over time (probably $\geq 21-24 \mathrm{RBCs} / \mathrm{phf}$ ), and histologic findings of M1, E1, and C1 > 1 (higher chance of renal deterioration). 


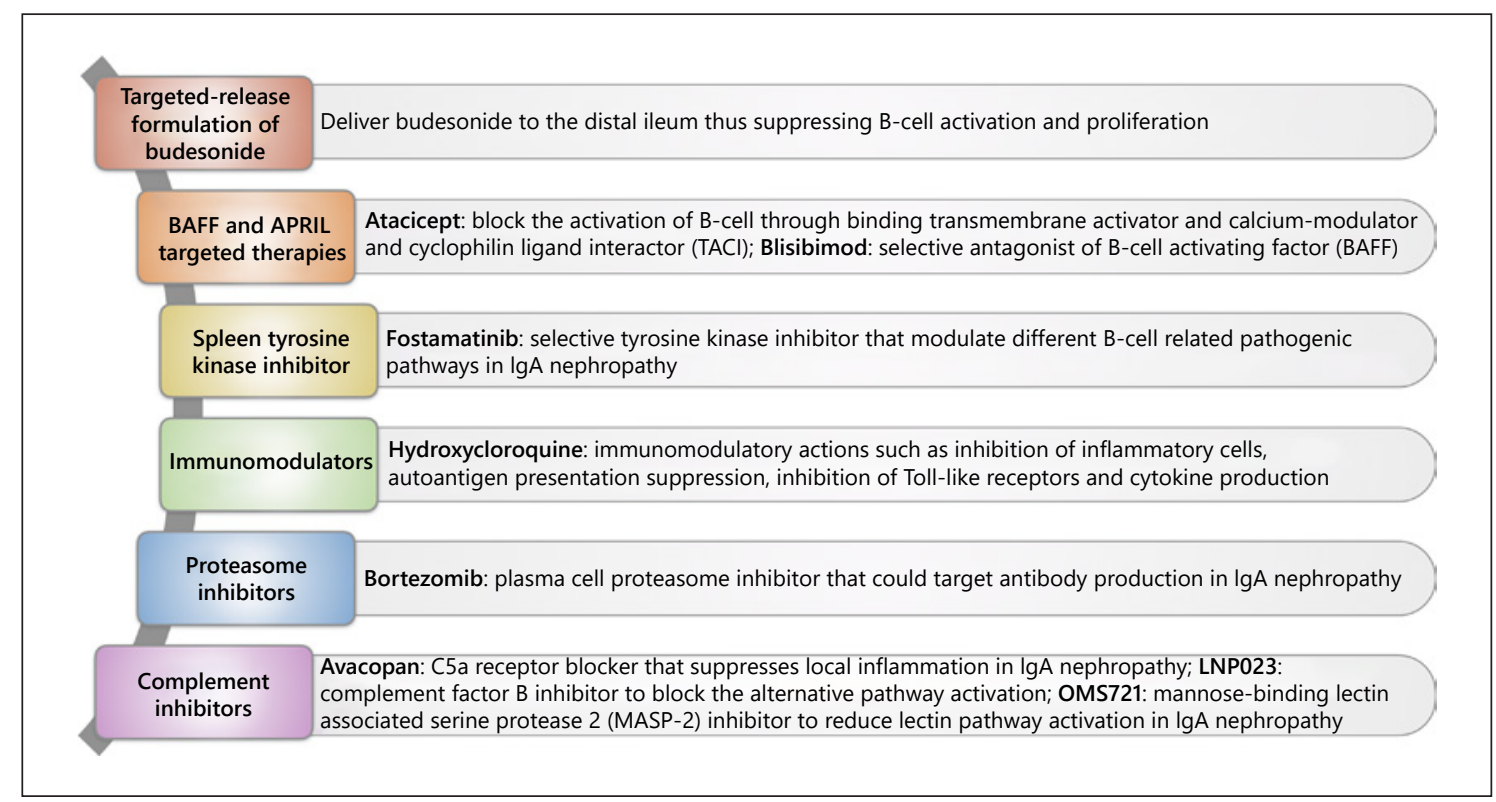

Fig. 4. Novel therapeutic strategies under investigation in IgAN. IgAN, IgA nephropathy; BAFF, B-cell activating factor; APRIL, a proliferation inducing ligand.

\section{Histopathological Characteristics, Prognostic and Future Therapeutic Marker?}

IgAN is characterized by diffuse mesangial IgA deposits, especially the subset of IgA1, in glomeruli. These deposits lead to the matrix expansion and mesangial proliferation accompanied by a variety of histopathological lesions [60] (see Fig. 3). Co-deposits of complement factor $\mathrm{C} 3$ are very common as well as deposits of IgG.

The histological presentation to the diagnosis might be an important parameter to consider, more if we take into account the new Oxford Classification. It is noteworthy that the morphologic pattern of injury, based mainly upon immunofluorescence findings, is very important in the IgAN evaluation. The Oxford Classification initially identified 4 lesions with independent prognostic value (loss of $50 \%$ of renal function or ESKD) from the usual clinical parameters of proteinuria, $\mathrm{BP}$, and eGFR $[61,62]$. Lesions are classified into mesangial hypercellularity (M0 or M1, depending on the absence or presence of mesangial proliferation in $>50 \%$ of the glomeruli), endocapillary proliferation (E0 or E1, absence or presence of any degree of endocapillary hypercellularity), lesions of segmental glomerulosclerosis ( $\mathrm{S} 0$ or $\mathrm{S} 1$, depending on the absence or presence of any glomerulosclerotic lesion), and tubular atrophy/interstitial fibrosis $(\mathrm{T})$, which graduates according to the severity of interstitial fibrosis (T0: 1-25\%; T1: 26-50\%; T2: >50\%).
The VALIGA (European Validation Study of the Oxford Classification of IgAN) also confirmed the association between some lesions such as M1, S1, T1/2 with renal outcomes and the association of M1 and E1 with subsequent increase in proteinuria [63]. These same results have also been demonstrated in children. In an elegant and necessary study, Barbour et al. [64] studied, for the first time, how the combination of the MEST score in adults with the clinical parameters at biopsy (proteinuria, BP, and eGFR) was able to predict the renal outcome with the same accuracy as clinical data over 2 years of follow-up.

Recently, a large analysis of IgAN patients have confirmed, using a similar methodology than VALIGA, the prognostic influence of the presence of crescents (cellular or fibrocellular) in the risk of progression of kidney disease, especially in those not immunosuppressed [65]. This has led to a modification of the MEST score that includes the number of crescents, the MEST-C (for "crescents"): C0: no crescents, C1: crescents in $<25 \%$ of glomeruli, and C2: in $>25 \%$. In summary, with all the results of the different retrospective studies carried out, it could be affirmed that the MEST-C score allowed risk stratification at an earlier time point and, in turn, offers the first opportunity to use histology as a predictor of renal outcome independently of clinical parameters.

However, the clinical practice guidelines continue to state that there is currently insufficient evidence to sup- 
port the decisions of immunosuppressive treatment in histological parameters. In order to resolve this mismatch between treatment decisions and histological findings, histology should be included in the next RCTs (see Treatment section). Based on this argument, in the new tool to predict the risk of ESKD in IgAN patients, the MEST score has been included [66].

In an attempt to improve its prognostic accuracy, the potential role of $\mathrm{C} 4 \mathrm{~d}$ staining (and other complement factors like FHR5) has also been studied for the discrimination of more aggressive forms [34, 35]. Probably, the study of microangiopathy (MA) lesions should also be included and clarified whether segmental glomerulosclerosis lesions (higher level of initial proteinuria) present with or without podocytopathic features.

\section{IgAN and Podocytopathy}

The role of podocyte in IgAN has been little studied. However, recent studies indicate that a major role is played by previous damage to the function and anatomy of the podocytes [67]. The podocytopathic changes are the consequence of initial alterations in the mesangial area, after continuous insult from the mesangium (see Fig. 4). This sustained insult results in the detachment of the podocytes from the glomerular basement membrane and its possible urinary loss (podocyturia). This damage has a clear clinical translation with the development of severe proteinuria in the early stages of the disease. This podocytopahty favors not only the development of focal glomerular lesions and segmental sclerosis but the progressive loss of renal function. Therefore, the podocitary damage in the IgAN is the result of the inflammation of the mesangium through that increasingly recognized continuous cross talk between mesangial cells and podocytes. Urokinase-type plasminogen activator receptor (uPAR) may participate in podocyte attachment. uPAR could play a fundamental role in the process of irreversible podocyte detachment through progression to kidney failure via glomerular podocytopenia and glomerulosclerosis [68]. In this sense, the use of amiloride could be useful to avoid podocyte detachment by blocking uPAR synthesis. Amiloride decreases the interaction of uPAR with podocyte actin and with integrins, reducing the risk of podocyturia and therefore proteinuria [69].

Moreover, the objective of this section is to show that the therapeutic target of the new drugs should not only be the mesangial cell but also the need to improve podocyte function and survival. On the other hand, these findings and statements are imbued with the findings of RubioNavarro et al. [70] that showed that podocytes are new cellular targets of hemoglobin-mediated renal damage. As a whole, a range is opened for the use of new and old drugs that may target the podocyte: renin-angiotensinaldosterone system (RAAS) blockade, amiloride (uPAR), abatacept (anti-CD80), and bortezomib (NF-kB inhibitor).

\section{IgAN and $M A$}

In recent years there have been several publications about MA lesions in IgAN, about their prognostic role and probable pathogenesis. MA lesions have a broad range of involvement (2-53\%) [71] but have consistently been associated with a higher percentage of hypertension (highlighting malignant hypertension), more severe histological lesions and finally ESKD.

Circulating macromolecules IgA1 may produce vascular damage of various degrees. Glomerular capillary wall activation triggers local inflammation involving the coagulation cascade with local complement activation, similar to the mechanisms involved in vasculitis. Endothelial cells are the first cells to be exposed to damaged and are clearly involved in the pathogenesis and progression of IgAN. A fundamental element is the cross talk between complement and coagulation. Certain coagulation enzymes can activate complement components from there that Markieewski et al. [72] wrote a paper with this suggestive title: "Complement and coagulation: strangers or partners in crime?"

Understanding the interrelation between complement and coagulation has fundamental clinical implications. The coagulation cascade activates complement (as thrombin can cleave C3), and complement activation is relevant also for the new therapeutic interventions. Endothelium exposure to C5b-9 resulted in von Willebrand factor (vWF) secretion leading to platelet activation and aggregation, causing a prothrombotic state. The vWF is a marker of endothelial dysfunction; our group showed how their plasma levels were increased in patients with IgAN maintaining a positive correlation with proteinuria levels [73]. The use of renin-angiotensin system inhibitors reduces vWF levels in parallel with proteinuria.

On the other hand, Gd-IgA1 selectively activates the AP of complement and start up the previously described mechanisms. MA is associated with C4d and C5b-9 deposits, the positivity of $\mathrm{C} 4 \mathrm{~d}$ together with the presence of thrombotic microangiopathy lesions in renal biopsies may serve to select a group of patients with worse renal survival and, therefore, should be followed closely, studied in depth and oriented towards different therapeutic approaches (possible close relationship between progres- 
sive cases of IgAN and defective complement regulation). In summary, glomerular injury in IgAN is associated with local and systemic activation of the complement system (see Fig. 1).

\section{Treatment}

A disease-specific treatment for IgAN patients is not currently available although several new molecules are under investigation. An individualized approach is essential to balance the risk-benefit of the different therapeutic options. Its wide range of clinical presentations and its dilated evolutionary course force this individualized and deeply weighed treatment.

There is a consistent agreement in the nephrological world that treatment with blockade of the RAAS, either with angiotensin-converting enzyme inhibitors or with angiotensin II receptor blockers, is the chosen treatment in patients with IgAN and proteinuria $>0.5-1 \mathrm{~g} /$ day and arterial hypertension (level of evidence 1 B) [49]. There are very few RCTs in IgAN; however, they have shown a significantly better renal survival in patients treated in this way, provided that the targets of proteinuria and BP are achieved $[74,75]$. The early antiproteinuric effect of RAAS blockade and its recognized local anti-inflammatory effect have demonstrated a clear renal benefit in the adult and child population [63]. Currently, treatment with RAAS inhibition alone or in combination is indicated in all patients with biopsy-proven IgAN and persistent abnormal proteinuria. The goal of treatment should be to maintain a proteinuria below $0.5-0.75 \mathrm{~g} /$ day and a BP lower than $125 / 75 \mathrm{~mm} \mathrm{Hg}$. A controversial issue has been the definition of the "point of no return," and following the results of different studies (especially VALIGA) [48, 63], we consider that the lower level of eGFR acceptable for initiation of therapy could be around $20-25 \mathrm{~mL} / \mathrm{min} / 1.73 \mathrm{~m}^{2}$. It is probably necessary to stratify the risk of patients. Recently, an international research collaboration externally validated has created a new predictive tool (BP; eGFR, proteinuria, and age at biopsy; use of angiotensin-converting enzyme inhibitor/angiotensin II receptor blocker or/and immunosuppression; and MEST score and race), available as a mobile-app, which can serve to identify high-risk subjects and may help physicians on treatment decisions [66].

Rigorous supportive care (RASi for BP and proteinuria, metabolic and lifestyle targets, food antigens, etc.) can be beneficial in one-third of patients with proteinuria $>0.75$ $3.5 \mathrm{~g} /$ day and stable renal function (no high risk of rapid progression), as demonstrated by the Intensive Supportive
Care plus Immunosuppression in IgA Nephropathy (STOP-IgAN) trial with a run-in period of 6 months [76].

Immunosuppressive Treatment: Towards the Search of the Patient with Risk of Progression

More than 10 years ago, G. Appel wrote an editorial recalling Shakespeare under the title: "To treat or not to treat IgAN? That is the question! [77]. Today, the usefulness of steroids and other immunosuppressive drugs is still a controversial topic. The KDIGO glomerular guidelines recommend, based on previous RCTs [78, 79], 6 months of corticosteroids in patients with persistent proteinuria $>1 \mathrm{~g}$ /day despite an optimal blockade of RAAS and adequate BP control but only in patients with an eGFR $>50 \mathrm{~mL} / \mathrm{min} / 1.73 \mathrm{~m}^{2}$. After the publication of the KDIGO guidelines, a retrospective study [63], but which analyzed a large number of patients using a "propensity score matching," showed a favorable effect of steroids. Interestingly, the beneficial effect was more evident in patients with higher degrees of proteinuria and with eGFR lower than $50 \mathrm{~mL} / \mathrm{min} / 1.73 \mathrm{~m}^{2}$.

Two recent RCTs with a greater number of patients and a more rigorous design have only partially resolved doubts about immunosuppressive treatment. The first and expected study was the STOP-IgAN trial [76]. Three hundred nine patients were included after 6 months of optimization of the support treatment that maintained a proteinuria $>0.75 \mathrm{~g} /$ day and an $\mathrm{eGFR}>30 \mathrm{~mL} / \mathrm{min} / 1.73$ $\mathrm{m}^{2}$. One-third of the patients reached a proteinuria $<0.75$ $\mathrm{g}$ /day during the run-in period, while the remaining twothirds were randomized to supportive treatment against 2 immunosuppressive treatment regimens (steroids if eGFR $>60 \mathrm{~mL} / \mathrm{min} / 1.73 \mathrm{~m}^{2}$ and steroids + cyclophosphamide/azathioprine if eGFR $<60 \mathrm{~mL} / \mathrm{min} / 1.73 \mathrm{~m}^{2}$ ). Although the number of patients who achieved complete remission was significantly higher in the immunosuppression group ( 5 vs. $18 \%$ ), there were no differences in the loss of renal function $\left(\geq 15 \mathrm{~mL} / \mathrm{min} / 1.73 \mathrm{~m}^{2}\right)$ during the 3 years of follow-up with fewer side effects in the support treatment group. The main weaknesses of the study were the short follow-up period (not sufficient to demonstrate beneficial effect in patients with modest proteinuria), the absence of histological data, the exclusion of progressive patients $(12 \%$ with proteinuria $>3.5 \mathrm{~g} /$ day and eGFR $<30 \mathrm{~mL} / \mathrm{min} / 1.73 \mathrm{~m}^{2}$ ), and the use of 2 different immunosuppressive therapies.

The second was the Therapeutic Evaluation of Steroids in IgA Nephropathy Global (TESTING) study [80]. It was a randomized, double-blind, controlled study to compare steroid treatment versus placebo. The initial design was 
intended to include $>700$ patients with proteinuria $>1 \mathrm{~g} /$ day and eGFR $>20 \mathrm{~mL} / \mathrm{min} / 1.73 \mathrm{~m}^{2}$. Despite favorable effects on proteinuria and eGFR decline, the risk of adverse effects was high in the treatment group, so it was suspended early after randomizing only 262 patients. This could be explained by the high dose of glucocorticoids $(0.6-0.8 \mathrm{mg} / \mathrm{kg} /$ day for 2 months) in the treated group ( $n=136)$ and the non-prophylactic use of trimethoprim-sulfamethoxazole (2 fatal pneumonia). Following these results, there is a new study in the recruitment phase (TESTING Low Dose Steroids) with reduced doses of steroids and use prophylactic trimethoprim-sulfamethoxazole during the first 3 months. It will be a tricontinental (multiethnic) study that will try to recruit about 500 patients stratified by OXFORD MEST-C score. The loss of glomerular filtration between the 2 studies was very different: in the STOP-IgAN, the control group (Caucasian population) showed an annual glomerular filtration loss of $1.6 \mathrm{~mL} / \mathrm{min} / 1.73 \mathrm{~m}^{2}$, whereas in the TESTING study (Asian population), the loss was $6.8 \mathrm{~mL} /$ $\min / 1.73 \mathrm{~m}^{2}$.

In summary, glucocorticoids have anti-inflammatory and immunosuppressive activity with direct effects on the cell nucleus. The pathogenesis of IgAN offers a suitable scenario for the use of glucocorticoids in the treatment of IgAN. Probably in future trials, hematuria and histological findings should be included. In this sense, the possibility of guiding glucocorticoid treatment according to histology is currently being tested in the Treatment of IgA Nephropathy According to Renal Lesions trial (NCT03188887) [81].

Finally, it is important to note that the highest percentage of side effects associated with glucocorticoids has been correlated with the degree of renal insufficiency [82]. Thus, in the 2 RCTs mentioned, $>30 \%$ of subjects with eGFR $<60 \mathrm{~mL} / \mathrm{min} / 1.73 \mathrm{~m}^{2}$ and full doses of drugs were used. Therefore, the dose of glucocorticoids should be adjusted to the renal function of the patient.

From a personal point of view, the use of glucocorticoids, prior to correct conservative treatment, should be reserved for patients with proteinuria $>1 \mathrm{~g} /$ day, maintained microhematuria and active lesions in the biopsy (M1, E1, C > 25\%) for patients with rapid deterioration of renal function and should be carefully evaluated in cases of proteinuria $<1 \mathrm{~g} /$ day with microhematuria and histological lesions of risk of progression (M1, E1, and S1 with podocytopathy). For patients with proteinuria between 1 and $2 \mathrm{~g} /$ day, but without histological lesions of activity, immunosuppressive treatment should generally be avoided unless it is associated with rapid deterioration of renal function.
The use of mycophenolate mofetil (MMF) has been very controversial in IgAN. Thus, the KDIGO guidelines have not recommended their use based on RCTs in the Caucasian population (early stopped) [83-85]. However, previous studies in the Asian population had a potential beneficial effect [86].

In this sense, a recent Chinese trial randomized patients of full dose of steroids or low dose of steroids with MMF for 6 months has reopened the debate [87]. One hundred seventy-six patients with proteinuria $\geq 1 \mathrm{~g} /$ day, eGFR $>30 \mathrm{~mL} / \mathrm{min} / 1.73 \mathrm{~m}^{2}$, and active proliferative lesions (C1 and E1) were included. After 1 year, complete remission was similar in both groups (53 and 48\%, respectively), but with less steroid-related adverse events in the MMF-treated group. In this study, renal biopsies were performed after treatment, showing histological improvement in both treatment arms. Previously, a retrospective study demonstrated, for the first time, the histological benefit of the use of MMF in 18 patients treated for an average of 28 months with MMF with improvement in endocapillary proliferation lesions and cellular/ fibrocellular crescents [88].

A similar pattern of low doses of steroids and MMF has been used by our group aiming at a clear benefit on the reduction of proteinuria and microhematuria with stabilization of renal function (unpublished data). A recent meta-analysis that reassessed the effectiveness of MMF (among 8 RCTs) concludes that MMF would have a place in the treatment of IgAN, especially in Asian population [89].

As for the rest of immunosuppressants, such as cyclophosphamide, azathioprine, and rituximab (more recently analyzed), have not offered clear advantages [90]. Even so, cyclophosphamide has demonstrated efficacy in uncontrolled studies in rapidly progressive forms and with a percentage of crescents $>50 \%[91,92]$.

Finally, a recent meta-analysis that included 13 trials with a total of 1321 patients (treatment with RASi and immunosuppressants) reflects that $75 \%$ of patients were unnecessarily treated because they had a low risk of progression, while $33 \%$ of patients who did not meet the inclusion criteria, despite a high histological risk, showed kidney function deterioration. These data are worrisome and should lead us to reflect on future RCTs [48].

The Mucosal Immune System Dysfunction as a Therapeutic Target: A Novel Concept with a Promising Future

An interesting therapeutic approach is the use of drugs aimed at the synthesis of gd-IgA1, called mucosal-associ- 
ated lymphoid tissue-targeted therapy. Budesonide is a capsule designed to release the drug to the distal ileum. The distal ileum is an area rich in Peyer's patches (B-cells predominate), the major sites of intestinal mucosa IgA production [93]. Targeted-release formulation of budesonide (TRF-budesonide and Nefecon ${ }^{\mathrm{TM}}$ ) is pharmacologically modified to be released in the distal ileum by resisting the gastric acid $\mathrm{pH}$ and releasing with the corresponding $\mathrm{pH}$ of the upper ileum, which makes it different from the budesonide used in inflammatory intestinal diseases. TRF-budesonide has a glucocorticoid effect more powerful than prednisone; however, after its digestive absorption, the active drug suffers an important hepatic pass with only $10 \%$ of the drug reaching systemic exposure [94].

Based on these observations, a phase $2 b$ trial evaluated the efficacy of TRF-budesonide. NEFIGAN study, a randomized, double-blind, placebo-controlled trial tested 2 regimes of budesonide ( 8 and $16 \mathrm{mg}$ ) against placebo in 149 patients with progressive biopsy-proven IgAN (eGFR $>45 \mathrm{~mL} / \mathrm{min} / 1.73 \mathrm{~m}^{2}$, proteinuria $>0.75 \mathrm{~g} /$ day) despite optimal RAAS blockade [95]. Over the 9-month treatment phase, patients from the TRF-budesonide groups presented a significant reduction in proteinuria (24.4\%) versus placebo (+2.7\%). At 12 months, the reduction was only significant (32\%) in the $16 \mathrm{mg}$ arm with eGFR stabilization. The safety profile of the drug was good (any important infectious event) despite the fact that $15 \%$ of patients dropped out of the trial. To confirm these findings, the NEFIGARD trial (NCT03643965) has been designed: a phase 3 , randomized, double-blind, placebo-controlled, multicenter study to compare the efficacy of $16 \mathrm{mg}$ of TRF-budesonide versus placebo.

\section{Manipulation of TLRs: HCQ}

TLRs play a fundamental role in the early innate immune response in response to the invasion of pathogens. TLR-9 is expressed in the B-cells of the mucous membranes. HCQ is an immunomodulator with a long halflife that inhibits mucosal and intrarenal TLR signaling. In turn, they inhibit the activation of inflammatory cells and the production of cytokines and chemokines in addition to suppressing the presentation of autoantigens [96].

The first phase 2, double-blind, randomized, placebocontrolled clinical trial has recently been published [97]. The trial was conducted in the Asian population, including patients with high risk for progressive IgAN (eGFR $>30 \mathrm{~mL} / \mathrm{min} / 1.73 \mathrm{~m}^{2}$; proteinuria: $0.75-3.5 \mathrm{~g} /$ day). The average glomerular filtration rate was $54 \mathrm{~mL} / \mathrm{min} / 1.73 \mathrm{~m}^{2}$ and the proteinuria $1.7 \mathrm{~g} /$ day despite an optimal dose of
RAAS for at least 3 months. The group with HCQ presented a significant reduction in proteinuria (48.4\%) compared to a $10 \%$ increase in the control group without differences in the percentage of change of eGFR after only 6 months of follow-up. The HCQ was adjusted according to renal function (200-400 $\mathrm{mg} /$ day) demonstrating a good safety profile. This safe drug may be a good alternative for future treatment, so some authors already included it in the support treatment armamentarium $[98,99]$.

\section{Emerging Therapies: New Pathogenic Pathways [100]} (See Fig. 4)

- Spleen tyrosine kinase may be a novel and selective therapeutic target for IgAN (also in pre-clinical models of vasculitis) [101]. It is an intracellular signaling pathway that participates in the maturation and survival of B-cells. Fostamatinib is an oral spleen tyrosine kinase inhibitor that decreases cell proliferation and the synthesis of pro-inflammatory mediators in mesangial cells exposed to IgA1 (NCT02112838).

- BAFF antagonists: Blisibimod (BRIGHT-SC, NCT02062684).

- Dual BAFF/APRIL inhibitor: Atacicept.

- Proteosome inhibitor: Bortezomib (NCT01103778).

- Angiotensin receptor blocker and endothelin receptor antagonist: Sparsentan (PROTECT trial, NCT03762850, phase 3). This is a randomized, multicenter, double-blind, parallelgroup, active-control study; currently in the recruitment phase, to investigate sparsentan versus an active control with irbesar$\tan$. The purpose of the study is to assess the potential benefit of sparsentan on kidney function by analyzing change in proteinuria and eGFR rate as compared to current the standard treatment. The primary outcome of the study is the urine protein/Cr ratio at week 36 after analyzing approximately 280 adult patients.

\section{Complement Inhibition in IgAN: In the Spotlight of IgAN Research}

The clear implication of complement in the pathogenesis of IgAN and its possible prognostic role translates into the numerous trials under way. In recent years, dysregulation of the complement system has been involved in a myriad of kidney diseases, although C3 glomerulopathy, atypical hemolytic uremic syndrome, and recently IgAN represent the 3 main complement-driven glomerular diseases [102].

\section{a. Factor B Inhibitor: LNP023}

Factor $\mathrm{B}(\mathrm{fB})$ is a fundamental protease in AP activation and amplification. Serum levels of $\mathrm{fB}$ are increased in patients with IgAN, which correlates with the activation of B-cells and the role of mucosal immunity in this disease [103]. The blockade of $\mathrm{fB}$ can have a physiopathological importance considering that the activation of the B-cells may be involved in the production of Gd-IgA1 and its an- 
tibodies and complement AP activation. LNP023 is an oral small molecule reversible $\mathrm{fB}$ inhibitor; this molecule is being tested in a phase IIa/IIb trial (NCT03373461) preliminarily demonstrating a significant reduction in proteinuria.

\section{b. MASP-2 Inhibitor: OMS721 (Narsoplimab)}

MASP-2 is a key effector enzyme of the LP. OMS721 is a monoclonal antibody to MASP-2 that led to significant reduction in proteinuria ( $72 \%$ in only 4 patients, presented as abstract: J Am Soc Nephrol 2017;28:749-50. SAPO278). A phase III, double-blind, randomized and placebo-controlled study (NCT03608033, ARTEMIS-IgAN) is in recruitment and aiming to evaluate the safety and efficacy of Narsoplimab in patients with IgAN, eGFR $\geq 30$ $\mathrm{mL} / \mathrm{min} / 1.73 \mathrm{~m}^{2}$ and $>1 \mathrm{~g} /$ day proteinuria [104].

\section{c. Anti-C3: Compstatin and APL-2}

C3 (and C5) receptor antagonists prevent the proliferation of cultured human mesangial cell stimulated by IgA 1 and produce a reduction in IL- 6 upregulation (key mediator of mesangial cell activation). Compstatin inhibits the activation of C3. APL-2 is a pegylated derivative of compstatin that binds $\mathrm{C} 3$ and prevents cleavage to $\mathrm{C} 3 \mathrm{a}$ and $\mathrm{C} 3 \mathrm{~b}$ by $\mathrm{C} 3$ convertase (daily subcutaneous infusion for 48 weeks). A phase 2 study to evaluate the safety and biologic activity of APL-2 in patients with IgAN, lupus nephritis, primary membranous nephropathy, and C3 glomerulopathy is now active (NCT03453619).

d. Anti-C5a Receptor Inhibitor: CCX168 (Avacopan) Inhibition of the AP component $\mathrm{C} 5 \mathrm{a}$ is attractive due to its role in neutrophil activation and migration and its effect on other inflammatory and thrombotic mechanisms. Avacopan is a small oral C5a receptor inhibitor that has demonstrated efficacy, safety, and steroid sparing in 2 vasculitis phase II trials [105]. Inhibition of the C5a receptor could have a direct beneficial effect on mesangial cells in murine models. A phase II study (NCT02384317) to evaluate the safety, tolerability, and efficacy of CCX168 in reducing proteinuria in IgAN patients receiving maximum tolerated RAAS blockade is being analyzed.

\section{e. Anti C5 Monoclonal Antibody: Eculizumab}

Eculizumab is a recombinant humanized monoclonal antibody (IgG2/4) that selectively inhibits C5, thereby preventing $\mathrm{C} 5 \mathrm{a}$ release and formation of the membrane attack complex (MAC and C5b-9). Eculizumab has been used only in isolated cases of young patients with progressive IgAN previously treated with several immunosuppressive drugs [106]. Eculizumab use was associated stabilization of renal function and proteinuria. Eculizumab has also been used in aggressive relapses of IgAN after kidney transplantation with very modest clinical effects, although this may be partially related to the timing of treatment. However, eculizumab is an extremely expensive drug at the moment and thus unlikely to enter into clinical practice for IgAN patients.

\section{f. C5 Suppression by an RNA Interference: ALN-CC5} (Cemdisiram)

Cemdisiram is a synthetic RNA interference designed to suppress liver C5 production, which may reduce terminal complement pathway activation and subsequent inflammation. A phase II, double-blind, randomized, and placebo-controlled study (NCT03841448) is in recruitment and aims to evaluate the safety and efficacy of Cemdisiram in patients with IgAN and $>1 \mathrm{~g}$ /day proteinuria.

\section{Conclusions and Knowledge Gaps}

"When is this true? What context do you need to be? Those questions are the source of knowledge. All important changes in the history of medicine, religion or science are based on a premise: reconsider what is considered knowledge." Sidharta Mukherijee

Despite the important advances in the understanding of the disease, there are still important knowledge gaps due to the high heterogeneity of the disease.

The lower baseline of eGFR to start treatment is unclear, and further studies are needed to define the "point of no return." The definition of "complete remission" should be included in routine clinical practice. It is necessary to establish when the immunosuppressive treatment is futile and what is the most suitable dose. In turn, therapies directed toward the anomalous synthesis of gd-IgA1 must demonstrate their efficacy in future trials.

To confirm the usefulness of immunosuppressive treatments and new therapeutic possibilities (enteric budesonide, complement blockers, etc.), well-designed studies are needed that include patients with sustained proteinuria and hematuria and that also take into account histological and immunohistochemical data. Finally, complement is in the spotlight of IgAN research. Unsurprisingly, given the complexity and heterogeneity of IgAN pathogenesis, a number of questions require clarification in the coming years. 


\section{Acknowledgements}

We thank all the members of the Spanish Group for the Study of Glomerular Diseases (GLOSEN group) for their valuable contribution to research in glomerular diseases.

\section{Conflict of Interest Statement}

The authors have no conflicts of interest to declare.

\section{Funding Sources}

Work in this study was supported by the Instituto de Salud Carlos III/Fondo Europeo de Desarrollo Regional (ISCIII/FEDER) grant PI16/01685 and Red de Investigación Renal (RedInRen) (RD12/0021/0029), the Autonomous Region of Madrid (S2017/ BMD-3673). This work has been made possible through my ISNfunded fellowship (author Leonella Luzardo).

\section{Author Contributions}

All authors contributed equally to this study, revised the paper, and approved the final version of the manuscript.

\section{References}

1 Berger J, Hinglais N. [Intercapillary deposits of IgA-IgG]. J Urol Nephrol. 1968;74(9):694-

2 McGrogan A, Franssen CF, de Vries CS. The incidence of primary glomerulonephritis worldwide: a systematic review of the literature. Nephrol Dial Transplant. 2011;26(2): 414-30.

3 Schena FP, Nistor I. Epidemiology of IgA nephropathy: a global perspective. Semin Nephrol. 2018;38(5):435-42.

4 Jarrick S, Lundberg S, Welander A, Carrero JJ, Höijer J, Bottai M, et al. Mortality in IgA nephropathy: a nationwide population-based cohort study. J Am Soc Nephrol. 2019;30(5): 866-76.

5 McQuarrie EP, Mackinnon B, McNeice V, Fox JG, Geddes CC. The incidence of biopsyproven IgA nephropathy is associated with multiple socioeconomic deprivation. Kidney Int. 2013;85(1):198-203.

6 Sallustio F, Curci C, Di Leo V, Gallone A Pesce F, Gesualdo L. A new vision of IgAN the missing link. Int J Mol Sci. 2020;21:189.

7 Kiryluk K, Li Y, Scolari F, Sanna-Cherchi S, Choi M, Verbitsky M, et al. Discovery of new risk loci for IgA nephropathy implicates genes involved in immunity against intestinal pathogens. Nat Genet. 2014;46(11):1187-496.

8 D'Amico G. Natural history of idiopathic IgA nephropathy and factors predictive of disease outcome. Semin Nephrol. 2004;24(3):179-96.

9 Reich HN, Troyanov S, Scholey JW, Cattran DC. Remission of proteinuria improves prognosis in IgA nephropathy. J Am Soc Nephrol. 2007;18(12):3177-83.

10 Julian BA, Quiggins PA, Thompson JS, Woodford SY, Gleason K, Wyatt RJ. Familial IgA nephropathy. Evidence of an inherited mechanism of disease. N Engl J Med. 1985; 312(4):202-8.

11 Heineke $\mathrm{MH}$, Ballering AV, Jamin A, Ben Mkaddem S, Monteiro RC, Van Egmond M. New insights in the pathogenesis of immunoglobulin A vasculitis (Henoch-Schönlein purpura). Autoimmun Rev. 2017;16(12):124653.

Update on IgA Nephropathy
12 Suzuki H, Kiryluk K, Novak J, Moldoveanu Z, Herr AB, Renfrow MB, et al. The pathophysiology of IgA nephropathy. J Am Soc Nephrol. 2011;22(10):1795-803.

13 Breedveld A, van Egmond M. IgA and FcaRI pathological roles and therapeutic opportunities. Front Immunol. 2019;10:553.

14 Coppo R, Amore A. Aberrant glycosylation in IgA nephropathy (IgAN). Kidney Int. 2004; 65(5):1544-7.

15 Moldoveanu Z, Wyatt RJ, Lee JY, Tomana M, Julian BA, Mestecky J, et al. Patients with IgA nephropathy have increased serum galactosedeficient IgA1 levels. Kidney Int. 2007;71(11): 1148-54.

16 Boyd JK, Cheung CK, Molyneux K, Feehally J, Barratt J. An update on the pathogenesis and treatment of IgA nephropathy. Kidney Int. 2012;81(9):833-43

17 Robert T, Berthelot L, Cambier A, Rondeau E, Monteiro RC. Molecular insights into the pathogenesis of IgA nephropathy. Trends Mol Med. 2015;21(12):762-75.

18 Barratt J, Smith AC, Feehally J. The pathogenic role of IgA1 O-linked glycosylation in the pathogenesis of IgA nephropathy. Nephrology. 2007;12(3):275-84.

19 Makita Y, Suzuki H, Kano T, Takahata A Julian BA, Novak J, et al. TLR9 activation induces aberrant IgA glycosylation via APRIL- and IL-6-mediated pathways in IgA nephropathy. Kidney Int. 2020;97(2):3409.

20 Muto M, Manfroi B, Suzuki H, Joh K, Nagai $\mathrm{M}$, Wakai S, et al. Toll-like receptor 9 stimulation induces aberrant expression of a proliferation-inducing ligand by Tonsillar Germinal Center B cells in IgA nephropathy. J Am Soc Nephrol. 2017;28(4):122738.

21 Bellur SS, Troyanov S, Cook HT, Roberts IS. Immunostaining findings in IgA nephropathy: correlation with histology and clinical outcome in the Oxford classification patient cohort. Nephrol Dial Transplant. 2011;26(8): 2533-6.
22 Novak J, Tomana M, Matousovic K, Brown R, Hall S, Novak L, et al. IgA1-containing immune complexes in IgA nephropathy differentially affect proliferation of mesangial cells Kidney Int. 2005;67(2):504-13.

23 Lai KN, Leung JC, Chan LY, Saleem MA, Mathieson PW, Tam KY, et al. Podocyte injury induced by mesangial-derived cytokines in IgA nephropathy. Nephrol Dial Transplant. 2009;24(1):62-72.

24 Tortajada A, Gutiérrez E, Pickering MC, Praga Terente M, Medjeral-Thomas N. The role of complement in IgA nephropathy. Mol Immunol. 2019;114:123-32.

25 Waldherr R, Rambausek M, Duncker WD, Ritz E. Frequency of mesangial IgA deposits in a non-selected autopsy series. Nephrol Dial Transplant. 1989;4(11):943-6.

26 Suzuki K, Honda K, Tanabe K, Toma H, Nihei $\mathrm{H}$, Yamaguchi $\mathrm{Y}$. Incidence of latent mesangial IgA deposition in renal allograft donors in Japan. Kidney Int. 2003;63(6):2286-94.

27 Gharavi AG, Kiryluk K, Choi M, Li Y, Hou P, Xie J, et al. Genome-wide association study identifies susceptibility loci for IgA nephropathy. Nat Genet. 2011;43(4):321-7.

28 Holmes LV, Strain L, Staniforth SJ, Moore I, Marchbank K, Kavanagh D, et al. Determining the population frequency of the CFHR3/ CFHR1 deletion at 1q32. PLoS One. 2013; 8(4):e60352.

29 Yeo SC, Goh SM, Barratt J. Is immunoglobulin A nephropathy different in different ethnic populations? Nephrology. 2019;24(9): 885-95.

30 Medjeral-Thomas NR, Lomax-Browne HJ Beckwith H, Willicombe M, McLean AG, Brookes P, et al. Circulating complement factor $\mathrm{H}$-related proteins 1 and 5 correlate with disease activity in IgA nephropathy. Kidney Int. 2017;92(4):942-52.

31 Tortajada A, Gutiérrez E, Goicoechea de Jorge E, Anter J, Segarra A, Espinosa M, et al. Elevated factor $\mathrm{H}$-related protein 1 and factor $\mathrm{H}$ pathogenic variants decrease complement regulation in IgA nephropathy. Kidney Int. 2017;92(4):953-63. 
32 Wyatt RJ, Julian BA, Rivas ML. Role for specific complement phenotypes and deficiencies in the clinical expression of IgA nephropathy. Am J Med Sci. 1991;301(2):115-23.

33 Zhu L, Guo WY, Shi SF, Liu LJ, Lv JC, Medjeral-Thomas NR, et al. Circulating complement factor $\mathrm{H}$-related protein 5 levels contribute to development and progression of IgA nephropathy. Kidney Int. 2018;94(1):150-8.

34 Espinosa M, Ortega R, Sánchez M, Segarra A, Salcedo MT, González F, et al. Association of C4d deposition with clinical outcomes in IgA nephropathy. Clin J Am Soc Nephrol. 2014; 9(5):897-904

35 Segarra A, Romero K, Agraz I, Ramos N, Madrid A, Carnicer C, et al. Mesangial C4d deposits in early IgA nephropathy. Clin J Am Soc Nephrol. 2018;13:258-64.

36 Stangou M, Alexopoulos E, Pantzaki A, Leonstini M, Memmos D. C5b-9 glomerular deposition and tubular alpha3beta1-integrin expression are implicated in the development of chronic lesions and predict renal function outcome in immunoglobulin A nephropathy. Scand J Urol Nephrol. 2008;42(4):373-80.

37 Gutiérrez E, Zamora I, Ballarín JA, Arce Y, Jiménez S, Quereda C, et al. Long-term outcomes of IgA nephropathy presenting with minimal or no proteinuria. J Am Soc Nephrol. 2012;23(10):1753-60.

38 Gutiérrez E, Praga M, Rivera F, Sevillano A, Yuste C, Goicoechea M, et al. Changes in the clinical presentation of immunoglobulin A nephropathy: data from the Spanish registry of glomerulonephritis. Nephrol Dial Transplant. 2018;33:472-7.

39 Gutiérrez E, González E, Hernández E, Morales E, Martínez MA, Usera G, et al. Factors that determine an incomplete recovery of renal function in macrohematuria-induced acute renal failure of IgA nephropathy. Clin J Am Soc Nephrol. 2007;2(1):51-7.

40 Praga M, Gutierrez-Millet V, Navas JJ, Ruilope LM, Morales JM, Alcazar JM, et al. Acute worsening of renal function during episodes of macroscopic hematuria in IgA nephropathy. Kidney Int. 1985;28(1):69-74.

41 Sevillano AM, Díaz M, Caravaca-Fontán F, Barrios C, Bernis C, Cabrera J, et al. IgA nephropathy in elderly patients. Clin J Am Soc Nephrol. 2019;14(8):1183-92.

42 Brodsky SV, Satoskar A, Chen J, Nadasdy G, Eagen JW, Hamirani M, et al. Acute kidney injury during warfarin therapy associated with obstructive tubular red blood cell casts: a report of 9 cases. Am J Kidney Dis. 2009;54(6):1121-6.

43 D’Amico G, Napodano P, Ferrario F, Rastald MP, Arrigo G. Idiopathic IgA nephropathy with segmental necrotizing lesions of the capillary wall. Kidney Int. 2001;59:682-92.

44 Tumlin JA, Hennigar RA. Clinical presentation, natural history, and treatment of crescentic proliferative IgA nephropathy. Semin Nephrol. 2004;24(3):256-68.

45 Barbour SJ, Reich HN. Risk stratification of patients with IgA nephropathy. Am J Kidney Dis. 2012;59(6):865-73.
46 Sevillano ÁM, Cabrera J, Gutiérrez E, Morales E, Mérida E, Huerta A, et al. Malignant hypertension: a type of IgA nephropathy manifestation with poor prognosis. Nefrologia. 2015; 35(1):42-9.

47 Donadio JV, Bergstralh EJ, Grande JP, Rademcher DM. Proteinuria patterns and their association with subsequent end-stage renal disease in IgA nephropathy. Nephrol Dial Transplant. 2002;17(7):1197-203.

48 Thompson A, Carroll K, A Inker L, Floege J, Perkovic V, Boyer-Suavet S, et al. Proteinuria reduction as a surrogate end point in trials of IgA nephropathy. Clin J Am Soc Nephrol. 2019;14(3):469-81.

49 Barrat J, Feehally J. Treatment of IgA nephropathy. Kidney Int. 2006;69:1934-8.

50 Herlitz LC, Bomback AS, Stokes MB, Radhakrishnan J, D'Agati VD, Markowitz GS. IgA nephropathy with minimal change disease. Clin J Am Soc Nephrol. 2014;9(6):10339.

51 Addis T. The effect of some physiological variables on the number of casts, red blood cells and white blood cells and epithelial cells in the urine of normal individuals. J Clin Invest. 1926;2(5):417-21.

52 Rhee RL, Davis JC, Ding L, Fervenza FC, Hoffman GS, Kallenberg CGM, et al. The utility of urinalysis in determining the risk of renal relapse in ANCA-associated vasculitis. Clin J Am Soc Nephrol. 2018;13(2):251-7.

53 Yuste C, Rubio-Navarro A, Barraca D, Aragoncillo I, Vega A, Abad S, et al. Haematuria increases progression of advanced proteinuric kidney disease. PLoS One. 2015;10(5): e0128575.

54 Kidney disease improving global outcomes (KDIGO) glomerulonephritis work group KDIGO, clinical practice guideline for glomerulonephritis. Kidney Int Suppl. 2012;2: 209-17.

55 Sevillano AM, Gutiérrez E, Yuste C, Cavero T, Mérida E, Rodríguez P, et al. Remission of hematuria improves renal survival in IgA nephropathy. J Am Soc Nephrol. 2017;28(10): 3089-99.

56 Floege J, Barbour SJ, Cattran DC, Hogan JJ, Nachman PH, Tang SCW, et al. Management and treatment of glomerular diseases (part 1): conclusions from a kidney disease: Improving global outcomes (KDIGO) controversies conference. Kidney Int. 2019; 95(2):268-80.

57 Bobart SA, Alexander MP, Shawwa K, Vaughan LE, Ghamrawi R, Sethi S, et al. The association of microhematuria with mesangial hypercellularity, endocapillary hypercellularity, crescent score and renal outcomes in immunoglobulin A nephropathy. Nephrol Dial Transpl. 2019 Dec 20.

58 Nicholls K, Walker RG, Dowling JP, KincaidSmith P. "Malignant" IgA nephropathy. Am J Kidney Dis. 1985;5(1):42-6.

59 Kincaid-Smith PS, Whitworth JA, Fairley KF. Mesangial IgA nephropathy in pregnancy. Clin Exp Hypertens. 1985;2(5):821-97.
60 Emancipator SN. IgA nephropathy: morphologic expression and pathogenesis. Am J Kidney Dis. 1994;23(3):451-62.

61 Working Group of the International IgA Nephropathy Network and the Renal Pathology Society; Cattran DC, Cattran DC, Coppo R, Cook HT, Feehally J, Roberts IS, et al. The Oxford classification of IgA nephropathy: rationale, clinicopathological correlations, and classification. Kidney Int. 2009;76(5):534-45.

62 Working Group of the International IgA Nephropathy Network and the Renal Pathology Society; Roberts IS, Roberts IS, Cook HT, Troyanov S, Alpers CE, Amore A, et al. The Oxford classification of IgA nephropathy: pathology definitions, correlations, and reproducibility. Kidney Int. 2009;76(5):546-56.

63 Coppo R, Troyanov S, Bellur S, Cattran D, Cook HT, Feehally J, et al. Validation of the Oxford classification of IgA nephropathy in cohorts with different presentations and treatments. Kidney Int. 2014;86(4):828-36.

64 Barbour SJ, Espino-Hernandez G, Reich HN, Coppo R, Roberts IS, Feehally J, et al. The MEST score provides earlier risk prediction in $\lg$ A nephropathy. Kidney Int. 2016;89(1):167-75.

65 Haas M, Verhave JC, Liu ZH, Alpers CE, Barratt J, Becker JU, et al. A multicenter study of the predictive value of crescents in IgA nephropathy. J Am Soc Nephrol. 2017;28(2): 691-701.

66 Barbour SJ, Coppo R, Zhang H, Liu Z-H, Suzuki Y, Matsuzaki K, et al. Evaluating a new international risk-prediction tool in IgA nephropathy. JAMA Intern Med. 2019;179(7): 942-52.

67 Trimarchi H, Coppo R. Podocytopathy in the mesangial proliferative immunoglobulin A nephropathy: new insights into the mechanisms of damage and progression. Nephrol Dial Transplant. 2019;34(8):1280-5

68 Trimarchi H, Canzonieri R, Schiel A, Costales-Collaguazo C, Stern A, Paulero M, et al. In IgA nephropathy, glomerulosclerosis is associated with increased urinary CD80 excretion and urokinase-type plasminogen activator receptor-positive podocyturia. Nephron Extra. 2017;7(2):52-61.

69 Trimarchi H, Paulero M, Canzonieri R, Schiel A, Iotti A, Costales-Collaguazo C, et al. In acute IgA nephropathy, proteinuria and creatinine are in the spot, but podocyturia operates in silence: any place for amiloride? Case Rep Nephrol. 2017;2017:1292531.

70 Rubio-Navarro A, Sanchez-Niño MD, Guerrero-Hue M, García-Caballero C, Gutiérrez E, Yuste $\mathrm{C}$, et al. Podocytes are new cellular targets of haemoglobin-mediated renal damage. J Pathol. 2018;244(3):296-310.

71 Trimarchi H, Coppo R. Glomerular endothelial activation, C4d deposits and microangiopathy in immunoglobulin A nephropathy. Nephrol Dial Transplant. 2019 Nov 22.

72 Markieewski MM, Nilsson B, Ekdahl KN, Mollnes TE, Lambris JD. Complement and coagulation: strangers or partners in crime? Trend Immunol. 2007;28:184-92. 
73 Hernández E, Toledo T, Álamo C, Mon C, Rodicio JL, Praga M. Elevation of von Willebrand factor levels in patients with IgA nephropathy: effect of ACE inhibition. Am J Kidney Dis. 1997;30(3):397-403.

74 Praga M, Gutiérrez E, González E, Morales E, Hernández E. Treatment of IgA nephropathy with ACE inhibitors: a randomized and controlled trial. J Am Soc Nephrol. 2003;14(6): 1578-83.

75 Van den Belt SM, Heerspink HJL, Gracchi V, de Zeeuw D, Wühl E, Schaefer F. Early proteinuria lowering by angiotensin-converting enzyme inhibition predicts renal survival in children with CKD. J Am Soc Nephrol. 2018; 29(8):2225-33.

76 Rauen T, Eitner F, Fitzner C, Sommerer C, Zeier M, Otte B, et al. Intensive supportive care plus immunosuppression in IgA nephropathy. N Engl J Med. 2015;373(23): 2225-36.

77 Appel GB. To treat or not to treat IgA nephropathy? That is the question! Clin J Am Soc Nephrol. 2006; 1(3):347-8.

78 Pozzi C, Bolasco PG, Fogazzi GB, Andrulli S, Altieri P, Ponticelli C, et al. Corticosteroids in IgA nephropathy: a randomised controlled trial. Lancet. 1999;353(9156):883-7.

79 Manno C, Torres DD, Rossini M, Pesce F, Schena FP. Randomized controlled clinical trial of corticosteroids plus ACE-inhibitors with long-term follow-up in proteinuric IgA nephropathy. Nephrol Dial Transplant. 2009; 24(12):3694-701.

$80 \mathrm{Lv}$ J, Zhang H, Wong MG, Jardine MJ, Hladunewich $\mathrm{M}$, Jha V , et al. Effect of oral methylprednisolone on clinical outcomes in patients with IgA nephropathy: the TESTING randomized clinical trial. JAMA. 2017;318(5): $432-42$.

81 Coopo R, Mariat C. Systemic corticosteroids and mucosal-associated lymphoid tissue-targeted therapy in IgA nephropathy: insight from the NEFIGAN study. Nephrol Dial Transpl. 2019 Dec 20.

82 Sarcina C, Tinelli C, Ferrario F, Pani A, De Silvestri A, Scaini $\mathrm{P}$, et al. Changes in proteinuria and side effects of corticosteroids alone or in combination with azathioprine at different stages of IgA nephropathy. Clin J Am Soc Nephrol. 2016;11(6):973-81.

83 Maes BD, Oyen R, Claes K, Evenepoel P, Kuypers D, Vanwalleghem J, et al. Mycophenolate mofetil in IgA nephropathy: results of a 3-year prospective placebo-controlled randomized study. Kidney Int. 2004;65(5):1842-
84 Frisch G, Lin J, Rosenstock J, Markowitz G, D’Agati V, Radhakrishnan J, et al. Mycophenolate mofetil (MMF) vs placebo in patients with moderately advanced IgA nephropathy: a double-blind randomized controlled trial. Nephrol Dial Transplant. 2005;20(10):213945.

85 Hogg RJ, Bay RC, Jennette JC, Sibley R, Kumar S, Fervenza FC, et al. Randomized controlled trial of mycophenolate mofetil in children, adolescents, and adults with IgA nephropathy. Am J Kidney Dis. 2015;66(5): 783-91.

86 Tang SC, Tang AW, Wong SS, Leung JC, Ho YW, Lai KN. Long-term study of mycophenolate mofetil treatment in IgA nephropathy. Kidney Int. 2010;77(6):543-9.

87 Hou JH, Le WB, Chen N, Wang WM, Liu ZS, Liu D, et al. Mycophenolate mofetil combined with prednisone versus full-dose prednisone in IgA nephropathy with active proliferative lesions: a randomized controlled trial. Am J Kidney Dis. 2017;69(6):788-95.

88 Beckwith H, Medjeral-Thomas N, Galliford J, Griffith M, Levy J, Lightstone L, et al. Mycophenolate mofetil therapy in immunoglobulin A nephropathy: histological changes after treatment. Nephrol Dial Transplant. 2017; 32(Suppl 1):i123-8.

89 Du B, Jia Y, Zhou W, Min X, Miao L, Cui W. Efficacy and safety of mycophenolate mofetil in patients with IgA nephropathy: an update meta-analysis. BMC Nephrol. 2017;18(1): 245.

90 Lafayette RA, Canetta PA, Rovin BH, Appel GB, Novak J, Nath KA, et al. A randomized, controlled trial of rituximab in IgA nephropathy with proteinuria and renal dysfunction. J Am Soc Nephrol. 2017;28(4):1306-13.

91 Roccatello D, Ferro M, Cesano G, Rossi D, Berutti S, Salomone M, et al. Steroid and cyclophosphamide in IgA nephropathy. Nephrol Dial Transplant. 2000;15(6):833-5.

92 Lv J, Yang Y, Zhang H, Chen W, Pan X, Guo $Z$, et al. Prediction of outcomes in crescentic IgA nephropathy in a multicenter cohort study. J Am Soc Nephrol. 2013;24(12):211825.

93 Cesta MF. Normal structure, function, and histology of mucosa-associated lymphoid tissue. Toxicol Pathol. 2006;34(5):599-608.

94 Fasci Spurio F, Aratari A, Margagnoni G, Clemente V, Moretti A, Papi C. Low bioavailability and traditional systemic steroids in IBD: can the former take over the latter? J Gastrointestin Liver Dis. 2013;22(1):65-71.
95 Fellström BC, Barratt J, Cook H, Coppo R, Feehally J, de Fijter JW, et al. Targeted-release budesonide versus placebo in patients with IgA nephropathy (NEFIGAN): a double-blind, randomised, placebo-controlled phase 2b trial. Lancet. 2017;389(10084): 2117-27.

96 Willis R, Seif AM, McGwin G Jr, MartinezMartinez LA, González EB, Dang N, et al. Effect of hydroxychloroquine treatment on pro-inflammatory cytokines and disease activity in SLE patients: data from LUMINA (LXXV), a multiethnic US cohort. Lupus. 2012;21(8):830-5.

97 Liu LJ, Yang YZ, Shi SF, Bao YF, Yang C, Zhu SN, et al. Effects of hydroxychloroquine on proteinuria in IgA nephropathy: a randomized controlled trial. Am J Kidney Dis. 2019;74(1):15-22.

98 Floege J. Antimalarials in IgA nephropathy: did our supportive therapy armamentarium just increase? Am J Kidney Dis. 2019;74(1): 6-8.

99 Gao R, Wu W, Wen Y, Li X. Hydroxychloroquine alleviates persistent proteinuria in IgA nephropathy. Int Urol Nephrol. 2017; 49(7):1233-41.

100 Yeo SC, Liew A, Barratt J. Emerging therapies in immunoglobulin A nephropathy. Nephrology. 2015;20(11):788-800.

101 McAdoo SP, Prendecki M, Tanna A, Bhatt T, Bhangal G, McDaid J, et al. Spleen tyrosine kinase inhibitor is an effective treatment for established vasculitis in a pre-clinical model. Kidney Int. 2020 Jan 16.

102 Cook HT. Complement and kidney disease. Curr Opin Nephrol Hypertens. 2013;22(3): 295-301.

103 van den Wall Bake AW, Daha MR, EversSchouten J, van Es LA. Serum IgA and the production of IgA by peripheral blood and bone marrow lymphocytes in patients with primary IgA nephropathy: evidence for the bone marrow as the source of mesangial $\operatorname{IgA}$. Am J Kidney Dis. 1988;12(5):410-4.

104 Smedbråten J, Mjøen G, Hartmann A, Åsberg A, Rollag H, Mollnes TE, et al. Low level of MAp44, an inhibitor of the lectin complement pathway, and long-term graft and patient survival; a cohort study of 382 kidney recipients. BMC Nephrol. 2016;17(1):148.

105 Jayne DRW, Bruchfeld AN, Harper L, Schaier M, Venning MC, Hamilton P, et al. Randomized trial of C5a receptor inhibitor avacopan in ANCA-associated vasculitis. J Am Soc Nephrol. 2017;28(9):2756-67.

106 Rosenblad T, Rebetz J, Johansson M, Békássy Z, Sartz L, Karpman D. Eculizumab treatment for rescue of renal function in IgA nephropathy. Pediatr Nephrol. 2014;29(11) $2225-8$. 